\title{
The Effects of Energy and Carbohydrate Restriction in Patients with Chronic Diabetes Mellitus*
}

\author{
J. R. Perkins, T.E.T. West, P.H. Sönksen, C. Lowy, and C. Iles \\ Departments of Medicine, Chemical Pathology and Dietetics, St. Thomas's Hospital and Medical School, London, England
}

Summary. Thirty-five freshly presenting, diabetic patients received 5 hour, $100 \mathrm{~g}$ oral glucose tolerance tests when first seen and after a period of carbohydrate and energy restriction. After treatment, the significant improvement in glucose tolerance was accompanied by increased insulin secretion and lower concentrations of blood ketone bodies, lactate, glycerol, FFA, triglycerides, cholesterol and pre-beta lipoprotein. There were no significant changes in serum growth hormone or blood pyruvate concentrations. Improvement in glucose tolerance was greater in patients who were obese $(>115 \%$ of desirable body weight for height) on presentation and was related to the improvement in insulin secretion and the diminished lipolysis. An hypothesis to explain the changes in insulin secretion is proposed. Eleven out of the 35 patients showed sufficient improvement in glucose tolerance to require no treatment other than diet.

Key words: Chronic (maturity onset) diabetes mellitus, glucose tolerance, insulin and growth hormone secretion, intermediary metabolites, lipids, diet treatment.

Carbohydrate restriction has been the keystone of most treatment regimes for diabetes mellitus for over 150 years [14]. Many patients with chronic (maturity-onset) diabetes require no therapy other than carbohydrate restriction to achieve remission of symptoms and maintenance of health. This form of treatment has the advantage of simplicity and avoids

* Presented in part at Ninth Annual Meeting of the European Society for Clinical Investigation, Rotterdam, 1975 the potential dangers and difficulties of insulin therapy or oral hypoglycaemic drugs. The mechanisms which are involved in determining good clinical and biochemical responses to carbohydrate and energy restriction are not well documented. Furthermore, there are no means of identifying, at the time of diagnosis, those patients who will respond to this form of treatment. We have investigated the biochemical changes that follow simple dietary advice on carbohydrate and energy restriction in a group of patients with chronic diabetes in an attempt to identify 1) the hormonal and biochemical changes associated with a satisfactory response to diet and 2) the clinical and biochemical features of those most likely to respond to this form of treatment.

\section{Patients and Methods}

\section{Patients}

Thirty-five freshly presenting, untreated diabetics were studied as out-patients. Three had previously been treated with diet or sulphonylureas and two were known to have had gestational diabetes, but these five had stopped all treatment, including diet, and had relapsed at the time of presentation. The group comprised ten women and 25 men, aged from 18 to 67 years, whose weights ranged from 52 to $95 \mathrm{~kg}$. Only patients whose percentage of desirable body weight for height (\% DBW, according to Metropolitan Life Insurance Tables) was less than $130 \%$ at the time of diagnosis were selected for study. Patients entering the study had no evidence of untreated disease other than diabetes mellitus. Two patients were receiving thyroid replacement therapy and three patients were being treated with mild anxiolytic agents. Each patient was given a $5 \mathrm{~h}$, 
$100 \mathrm{~g}$ oral glucose tolerance test (OGTT) on presentation and after the period of dietary treatment. If patients were of normal weight ( $85-115 \% \mathrm{DBW})$, the second OGTT was performed approximately one month after the first. Those patients whose weight exceeded $115 \%$ DBW were maintained on diet until their weight had fallen to within $15 \%$ of DBW before the second test was performed. The more obese patients therefore tended to remain on diet for a longer period (up to 33 weeks).

\section{OGTTS}

Patients were advised to continue their usual diet until the day of their first OGTT. Carbohydrate intake was not increased before the second OGTT. All tests were done in the morning, after an overnight fast $(\geqslant 11 \mathrm{~h})$ and patients remained recumbent throughout the tests. A plastic cannula was inserted into a forearm vein and kept patent with 0.15 $\mathrm{MNaCl}$. After two fasting blood samples (separated by $10 \mathrm{~min}$ ) had been taken, the patients drank, within $10 \mathrm{~min}, 100 \mathrm{~g}$ glucose in $250 \mathrm{ml}$ water, flavoured with unsweetened lemon juice. Blood sampling was continued up to $5 \mathrm{~h}$ after the end of glucose ingestion and measurements were made of the concentration of: glucose, insulin (IRI), growth hormone $(\mathrm{GH})$, lactate, pyruvate, 3-hydroxybutyrate, acetoacetate, free fatty acids (FFA) and glycerol. Fasting plasma cholesterol and triglycerides and lipoprotein electrophoretic pattern were also measured at each OGTT.

\section{Diet}

All patients were initially interviewed by a dietitian and their usual diet was assessed for carbohydrate and total energy intake. This diet was continued until the first OGTT. Patients were seen again by the dietitian and instructed to reduce their carbohydrate intake. No increase in protein or fat intake was advised, so that energy intake fell in all patients, although more stringent energy restriction was advised to the more obese patients ( $>115 \%$ DBW).

\section{Analytical Methods}

Blood glucose was measured by an automated glucose oxidase method. $[19,20]$ Serum IRI and GH concentrations were measured by a combined double antibody radioimmunoassay [18]. Enzymatic methods were used to measure blood lactate and pyruvate [8], 3-hydroxybutyrate and acetoacetate [25] and glycerol [11]. Blood for metabolite estimation was taken into an equal volume $(5 \mathrm{ml})$ of $1 \mathrm{M}$ perchloric acid and stored deep frozen until analysed. The coefficient of variation of the measurements was less than 5\%. FFA [2] and triglycerides [10] were measured fluorimetrically in extracts of plasma. Plasma cholesterol was measured colorimetrically [12]. Lipoprotein electrophoresis was carried out in agarose gel and the proportion of staining in each band was measured with an integrating reflecting densitometer.

\section{Analysis of Results}

Differences between values at each OGTT were assessed by analysis of variance. Values measured throughout each OGTT were first assessed by a 3-way analysis of variance, with patients, OGTT number and times of measurement in OGTTs as factors (OGTT number and times in tests were taken as fixed effects and patients as a random effect) [26]. There were the expected significant differences between patients and between times of measurement in OGTTs, but the main interest was in differences between the first and second tests. Where response curves were not significantly non-parallel (i. e. there was no significant 2-way interaction between OGTT number and times in test), the residual estimate of variance was used for the $t$ test significances given in the Figures. Where shapes of response curves changed on treatment, significances of the simple main effect of OGTT number (assessed by 2-way analyses of variance at each time of measurement in OGTTs, identical for these data to a 'paired' Student's $t$ test) are given. This method was also used for the variables measured only once at the start of each OGTT.

Relationships of changes in one variable to changes in others were investigated by analysis of covariance or of correlation. For each variable measured at each point during OGTTs, differences between values at OGTT 1 and OGTT 2 were calculated. The significances of their interrelations were assessed by analysis of covariance, with patients and times of measurements in OGTTs as factors. Changes in variables measured only once at each OGTT were related to other changes by simple correlation analysis.

We separately examined the results from patients with the least marked glucose intolerance after diet treatment, since this group appeared to be adequately controlled by this means alone. We divided the patients into two groups on the basis of the sum of their blood glucose concentrations at 0,1 , 2 and $3 \mathrm{~h}$ (SUMBG) during the second OGTT. Patients whose SUMBG was less than $44.4 \mathrm{mmol} / 1$ $(800 \mathrm{mg} / 100 \mathrm{ml})$ were judged to be "Responders" 
to diet therapy, while those whose SUMBG was $>44.4 \mathrm{mmol} / \mathrm{l}$ were taken as "Non-responders". The significance of differences between the two groups was assessed (for continuous variables) by Student's $t$ test or (for discrete variables) by chi squared tests.

We also divided the patients into two groups on the basis of \% DBW on presentation (at OGTT 1). Patients whose DBW was $\leqslant 115 \%$ were classed as non-obese and those whose DBW was $>115 \%$ were classed as obese.

\section{Results}

\section{Diet and Weight Change}

On presentation, dietary assessment revealed an average daily carbohydrate intake of $260 \mathrm{~g}$ (range $85-400 \mathrm{~g}$ ) and an average energy intake of 10.4 MJ* (range 4.4-13.7 MJ). The average prescribed diet contained $142 \mathrm{~g}$ carbohydrate (range $80-245 \mathrm{~g}$ ) and the energy content was $6.8 \mathrm{MJ}$ (range 4.3-10.5 MJ). The mean duration of diet treatment was 59 days (range 21-232 days). Of the 35 patients, 29 lost weight (up to $7.5 \mathrm{~kg}$ ), one gained weight by $1.9 \mathrm{~kg}$ and five stayed at the same weight. The average weight of the group fell from 68.9 $\pm 1.8 \mathrm{~kg}$ (mean $\pm \mathrm{SEM}$ ) to $66.6 \pm 1.7 \mathrm{~kg}(\% \mathrm{DBW}$ fell from $106.8 \pm 2.0$ to $103.2 \pm 1.8$ ).

\section{Biochemical Changes}

Mean concentrations of glucose, IRI and GH at each OGTT are shown in Figure 1. After diet, there was a marked improvement in fasting glucose concentration and in glucose tolerance. The shape of the 2 nd response curve changed $(p<0.05)$, the peak glucose concentration being reached earlier, the rise from fasting to peak values being smaller and values returning to the fasting concentration by $5 \mathrm{~h}$. Mean changes were significant at all times of measurement. While fasting IRI concentrations were similar before and after treatment, the response curve in the second OGTT was improved significantly $(\mathrm{p}<0.01)$ compared with the first. Treatment produced significantly higher insulin concentrations at the times shown, as well as a significant change in shape of the response curve. The patterns of growth hormone response were similar in both OGTTs.

Figure 2 shows FFA, glycerol, ketone bodies, lactate and pyruvate concentrations throughout the OGTTs. Treatment did not change the shape of the FFA response curve, but gave lower concentrations
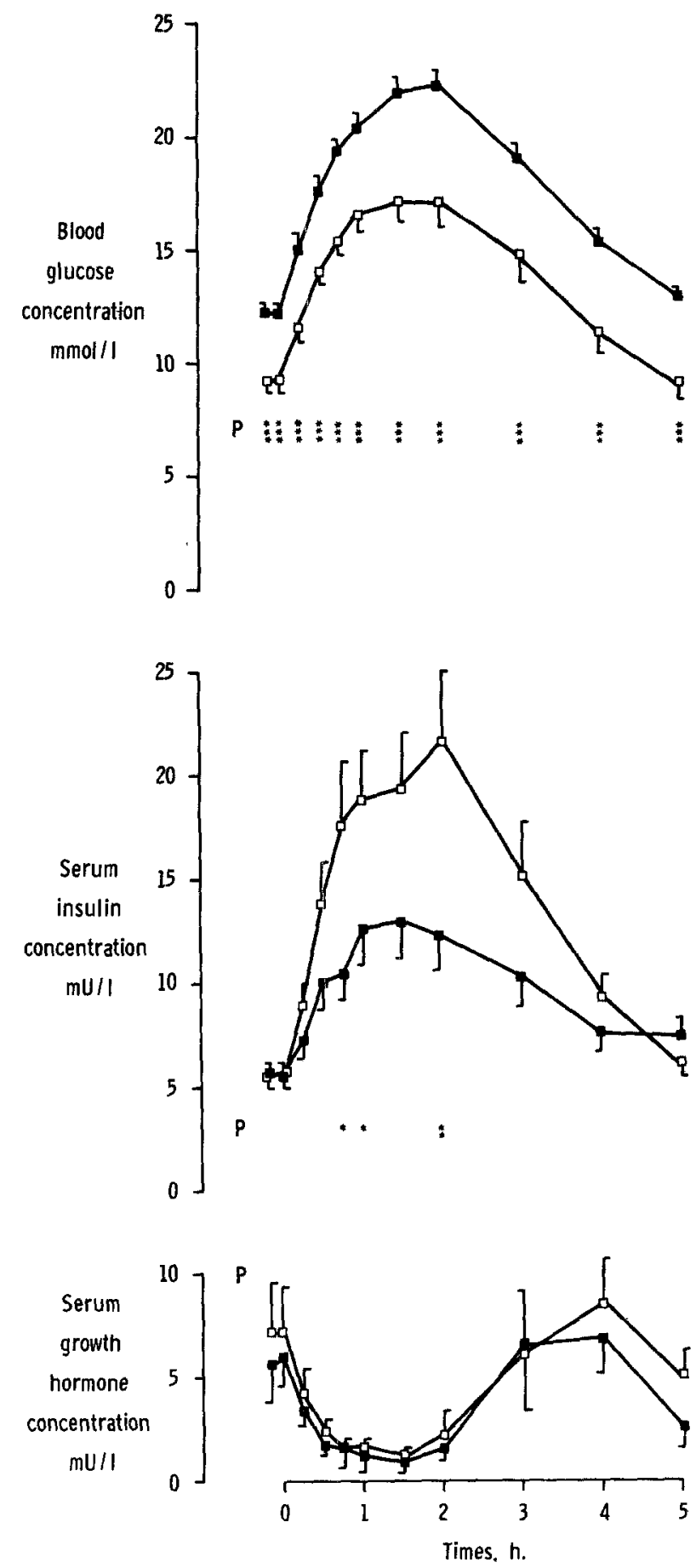

Fig. 1. Glucose, insulin and growth hormone concentrations before and after treatment. Mean values at OGTT 1 are shown by and at OGTT 2 by $\square$ (bars indicate SEMs). The significance (p) of the difference between values at OGTTs 1 and 2 is indicated: $*, p \leqslant 0.05 ;:, p \leqslant 0.01, *, p \leqslant 0.001$

up to $4 \mathrm{~h}$. The effect on glycerol was to change the response curve's shape ( $p<0.05)$, as well as to give lower concentrations between 1 and $4 \mathrm{~h}$ post glucose. Although the fall in ketone body concentrations after treatment did not reach statistical significance, 

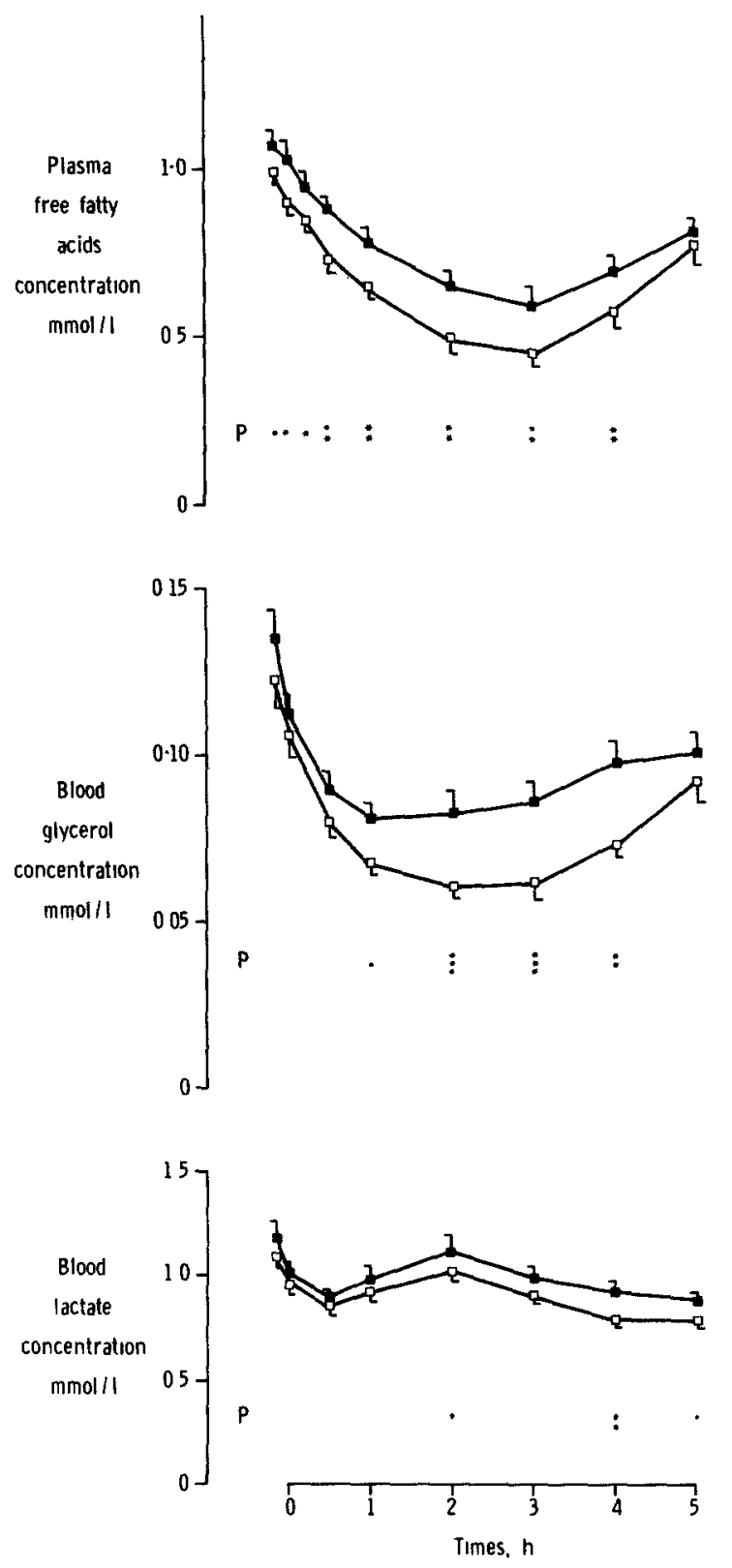
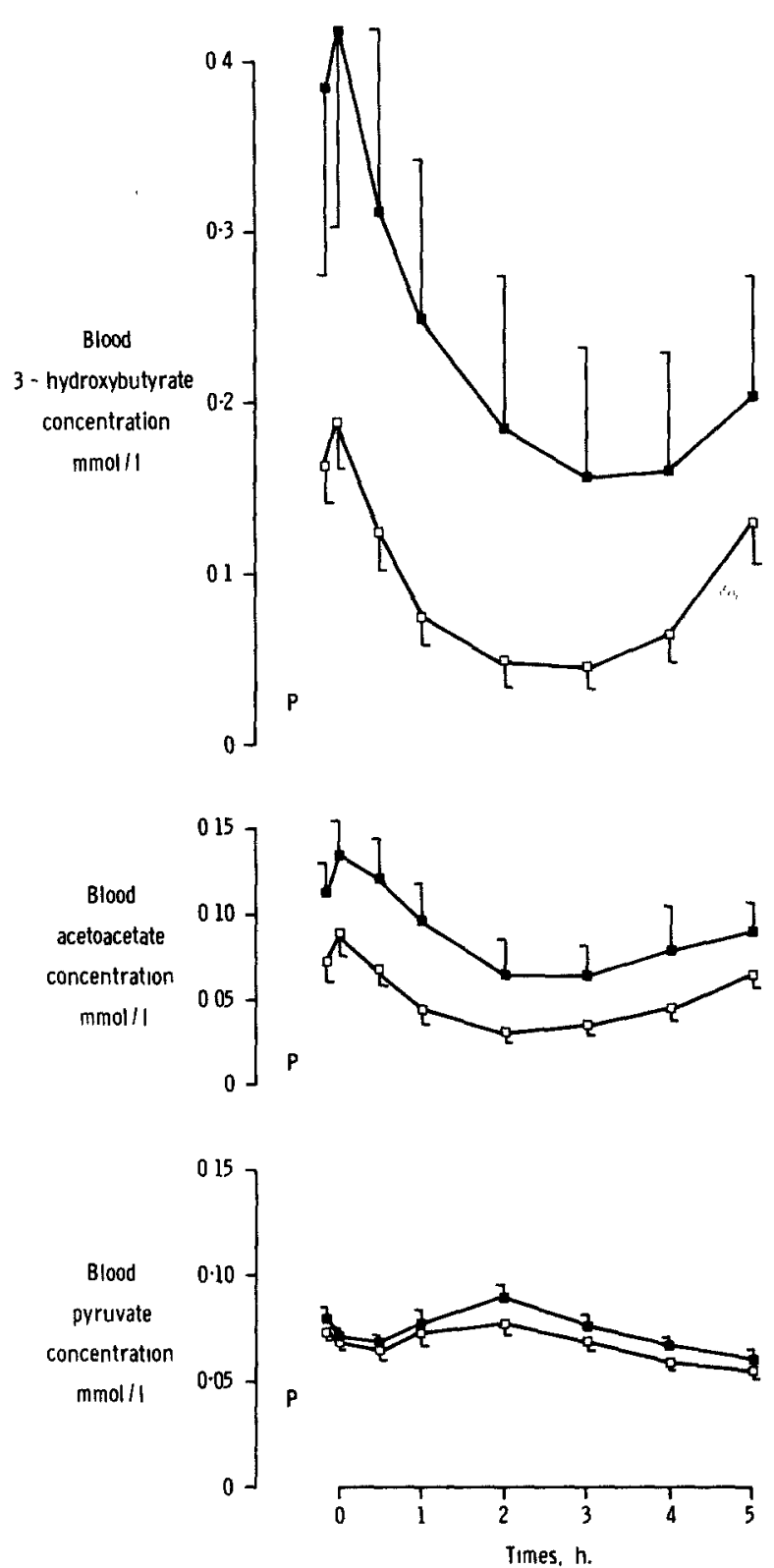

Fig. 2. Intermediary metabolite concentrations before and after treatment. Symbols are the same as those given in the legend to Figure 1

the shape of the 3-hydroxybutyrate curve was changed significantly $(p<0.01)$, presumably a reflection of the lower fasting concentrations. (These results were biased by three patients, who had very high ketone body concentrations at their first OGTT. Their total fasting ketone body concentrations fell from over $1.5 \mathrm{mmol} / 1$ to less than $0.25 \mathrm{mmol} / 1$ after diet). Treatment had no effect on the shapes of the response curves of lactate and pyruvate, but did produce lower lactate concentrations at 2,4 and $5 \mathrm{~h}$ in OGTT 2. Mean [lactate]/[pyruvate] and [3-hydroxybutyrate]/[acetoacetate] ratios were not appreciably abnormal at the first OGTT and showed no significant changes on treatment.
Fasting cholesterol and triglycerides and the proportion of prebeta lipoprotein all fell significantly after diet therapy (Fig. 3). The fall in the proportion of beta lipoprotein, unlike that of cholesterol, was not significant. There was a significant relative increase in alpha lipoprotein.

\section{Relation of Changes in Different Variables}

Table 1 shows the significances of the covariances of variables measured throughout OGTTs. Increases in insulin secretion between OGTTs 1 and 2 were significantly related to decreases in concentrations of glucose, lactate, ketone bodies and FFA. Changes in 


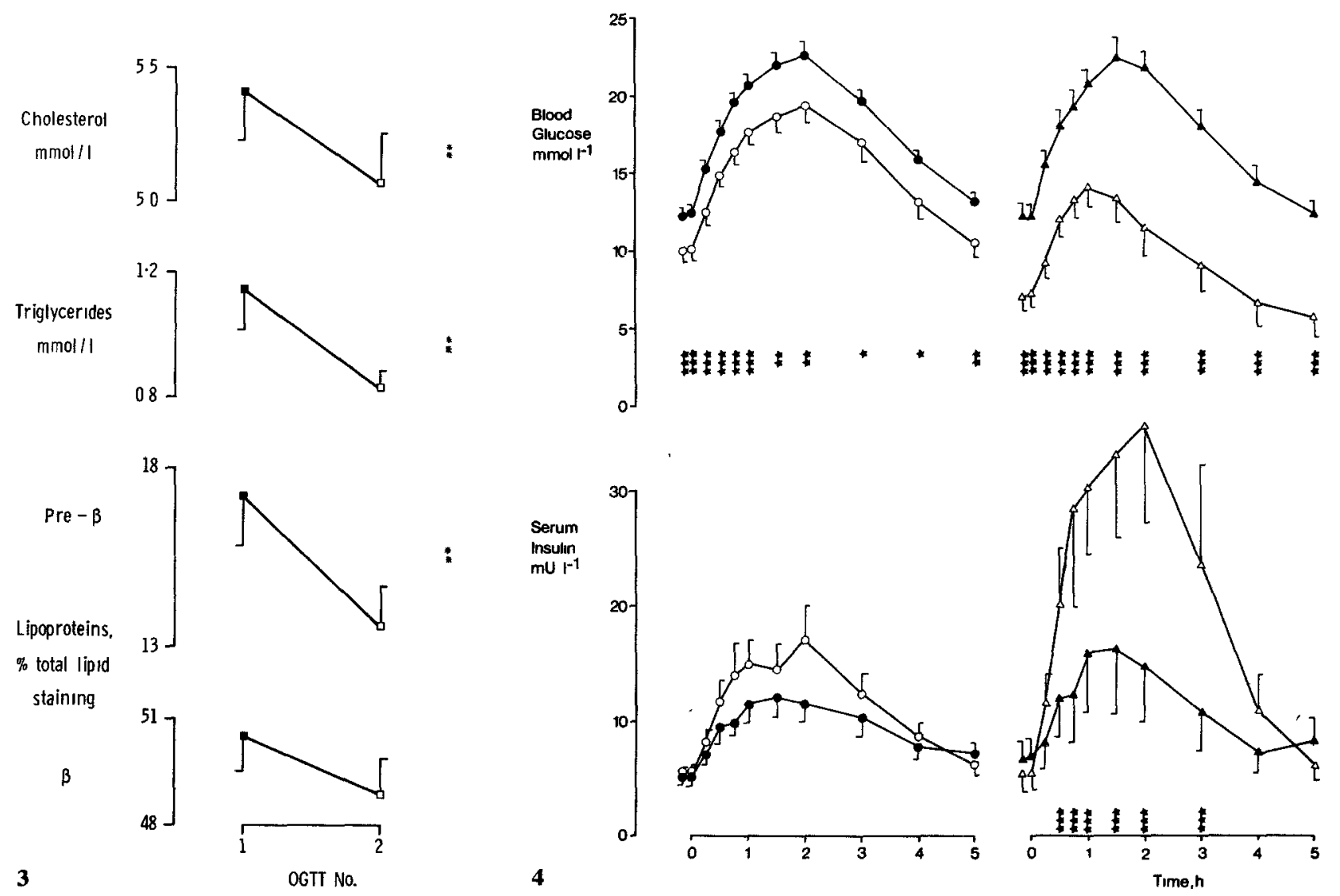

Fig. 3. Fasting lipid values before and after treatment. Symbols are the same as those given in the legend to Figure 1

Fig. 4. Glucose and IRI concentrations before (solid symbols) and after (open symbols) diet treatment in non-obese patients (left hand panel) and obese patients (right hand panel). Other symbols as in Figure 1

Table 1. Relation of changes in different compounds at each point during OGTTs (see text for explanation). The table gives the significance $(p)$ of the variance ratio $(F)$ from analyses of covariance of concentration changes between OGTTs 1 and $2(\triangle)$ for each pair of compounds. NS = not significant. Asterisks indicate an inverse correlation

\begin{tabular}{|c|c|c|c|c|c|c|c|c|c|c|c|c|c|c|c|c|}
\hline \multirow[b]{2}{*}{$\triangle$} & \multicolumn{2}{|c|}{ Insulin } & \multicolumn{2}{|c|}{$\begin{array}{l}\text { Growth } \\
\text { Hormone }\end{array}$} & \multicolumn{2}{|c|}{ Glucose } & \multicolumn{2}{|c|}{ Lactate } & \multicolumn{2}{|c|}{ Pyruvate } & \multicolumn{2}{|c|}{$\begin{array}{l}\text { 3-Hydroxy- } \\
\text { butyrate }\end{array}$} & \multicolumn{2}{|c|}{$\begin{array}{l}\text { Aceto- } \\
\text { acetate }\end{array}$} & \multicolumn{2}{|c|}{ Glycerol } \\
\hline & $\mathrm{F}$ & $\mathrm{p}$ & $\mathbf{F}$ & $\mathrm{p}$ & $\mathbf{F}$ & $\mathrm{p}$ & $\mathrm{F}$ & $\mathbf{p}$ & $\mathbf{F}$ & $p$ & $\mathbf{F}$ & $\mathrm{p}$ & $\mathbf{F}$ & $\mathrm{p}$ & $\mathbf{F}$ & $\mathrm{p}$ \\
\hline Free Fatty Acids & $17.0^{*}$ & $<.01$ & $0.1 *$ & NS & 17.2 & $<.01$ & 2.9 & NS & 0.3 & NS & 71.7 & $<.01$ & 97.4 & $<.01$ & 83.7 & $<.01$ \\
\hline Glycerol & $3.4^{*}$ & NS & $0.7^{*}$ & NS & 19.2 & $<.01$ & 6.4 & $<.05$ & 3.6 & NS & 14.2 & $<.01$ & 15.0 & $<.01$ & & \\
\hline Acetoacetate & $32.9 *$ & $<.01$ & $0.2^{*}$ & NS & 29.2 & $<01$ & 8.9 & $<.01$ & 14.3 & $<.01$ & 1259. & $6<.01$ & & & & \\
\hline $\begin{array}{l}\text { 3-Hydroxy- } \\
\text { butyrate }\end{array}$ & $30.8 *$ & $<.01$ & $0.004^{*}$ & *NS & 24.0 & $<.01$ & 4.3 & $<05$ & 14.4 & $<.01$ & & & & & & \\
\hline Pyruvate & $0.3^{*}$ & NS & $04^{*}$ & NS & 12.2 & $<.01$ & 91.9 & $<.01$ & & & & & & & & \\
\hline Lactate & $7.7^{*}$ & $<.01$ & $0.05^{*}$ & NS & 1.0 & NS & & & & & & & & & & \\
\hline Glucose & $24.1^{*}$ & $<.01$ & $0.1^{*}$ & NS & & & & & & & & & & & & \\
\hline Growth Hormone & $0.8 *$ & NS & & & & & & & & & & & & & & \\
\hline
\end{tabular}

growth hormone did not correlate with any other variable. The majority of remaining variables were significantly related, especially when they were linked metabolically (i. e. 3-hydroxybutyrate and acetoacetate, lactate and pyruvate). Changes in glycerol were related to those of glucose, ketone bodies and FFA. Variables with more distant biochemical rela- tionships and those which changed least on treatment showed the weakest correlations.

The change in fasting cholesterol showed a weak $(\mathrm{p}<0.05)$ correlation with the changes in ketone bodies, but not with changes in beta lipoprotein. Neither absolute weight (and \% BDW) nor the changes in either on treatment correlated with the 
Table 2. 'Responders' and 'Non-responders'. Clinical data at diagnosis. NS indicates not significant

\begin{tabular}{|c|c|c|c|}
\hline & Responders & Non-responders & $\mathbf{P}$ \\
\hline Number & 11 & 24 & \\
\hline Female & 2 & 8 & NS \\
\hline Male & 9 & 16 & $\mathrm{NS}^{\prime}$ \\
\hline Retinopathy & 1 & 7 & NS \\
\hline $\begin{array}{l}\text { Peripheral } \\
\text { neuropathy }\end{array}$ & 1 & 3 & NS \\
\hline $\begin{array}{l}\text { Vascular } \\
\text { disease }\end{array}$ & 0 & 2 & NS \\
\hline Family histor & & & \\
\hline of diabetes & 4 & 9 & NS \\
\hline Age (years) & $43(31-67)$ & $50(18-64)$ & NS \\
\hline Height (cm) & $174(160-185)$ & $166(126-183)$ & $<0.05$ \\
\hline Weight (kg) & $78(64-95)$ & $66(52-86)$ & $<0.001$ \\
\hline$\%$ DBW & $115(87-130)$ & $103(85-127)$ & $<0.01$ \\
\hline $\begin{array}{l}\text { Weight } \\
\text { change }(\mathrm{kg})\end{array}$ & \multicolumn{3}{|c|}{$-3 \cdot 0(-7 \cdot 5$ to $1 \cdot 9)-2 \cdot 0(-7 \cdot 0$ to 0$) \mathrm{NS}$} \\
\hline $\begin{array}{l}\text { Duration of } \\
\text { diet (days) }\end{array}$ & $77(28-232)$ & $50(21-231)$ & NS \\
\hline
\end{tabular}

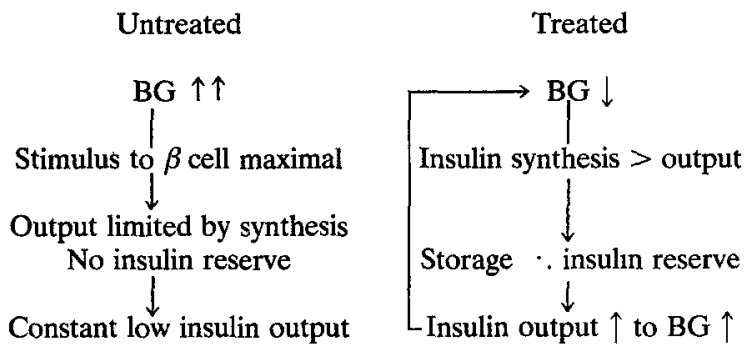

Fig. 5. Proposed mechanism of the response to dietary therapy. See text for explanation

improvements in glucose tolerance, insulin secretion or other changes.

\section{Responders and Non-responders}

When the response to carbohydrate restriction was classified according to the SUMBG at the second test, eleven patients were judged to be Responders and 24 Non-responders. Clinical details of these patients on presentation are given in Table 2. Sexual and ethnic distributions between the two groups were similar, as were the assessed diets at presentation and the dietary advice given. There was a higher incidence of vascular complications in the group of Non-responders, although the difference between the two groups did not reach statistical significance. Responders were significantly taller and relatively more overweight than Non-responders at the time of presentation. The only biochemical variables differing significantly between the Responders and Non-responders at the time of presentation were a lower mean fasting $\mathrm{GH}$ concentration $(2.6 \pm 1.2$ and $7.6 \pm 1.8 \mathrm{mu} / \mathrm{l}, \mathrm{p}<0.05)$ and higher mean fa- sting triglycerides $(1.58 \pm 1$ and $0.94 \pm$ $0.46 \mathrm{mmol} / 1, \mathrm{p}<0.05)$ and pre-beta lipoprotein values $(21 \pm 11$ and $15 \pm 6 \%, \mathrm{p}<0.05)$ in $\mathrm{Re}-$ sponders. Mean plasma insulin concentrations and glucose tolerance were identical in the two groups at presentation. The most striking difference between the two goups at the second OGTT (apart from the difference in glucose tolerance) was a marked improvement in IRI concentrations after oral glucose in Responders. In Non-responders mean IRI response to oral glucose was unchanged after carbohydrate restriction. Furthermore, in Responders mean concentrations of glycerol and 3-hydroxybutyrate were lower than in Non-responders during the second test.

\section{Obese and Non-obese}

At OGTT 126 patients were non-obese (17 men and nine women, weight $64.9 \pm 1.6 \mathrm{~kg}$, DBW 102 $\pm 2 \%$ ) and nine were obese (eight men and one woman, weight $80.4 \pm 2.6 \mathrm{~kg}$, DBW $122 \pm 2 \%$ ). The obese group lost significantly more weight than the non-obese $(4.6 \pm 0.9 \mathrm{~kg}$ versus $1.5 \pm 0.4 \mathrm{~kg}$ respectively, $\mathrm{p}<0.0001)$. There were no significant differences in glucose or IRI between the two groups at OGTT 1 (Fig. 4). Both groups showed significant improvements in glucose after treatment and the improvement was significantly greater in the obese group from 2 to $5 \mathrm{~h}$. In the obese group postglucose IRI concentrations increased significantly after treatment although mean fasting IRI did not change. The non-obese group showed no significant increase in IRI.

Six of the nine obese patients and three of the 24 non-obese patients were Responders. The proportion of Responders was significantly greater in the obese than in the non-obese group $\left(x^{2}=7\right.$, $\mathrm{p}<0.01)$.

\section{Discussion}

In this study we have shown that, in a group of untreated diabetic patients, carbohydrate and energy restriction with weight loss leads to improvement in glucose tolerance and insulin secretion. In parallel with these changes, there was evidence of diminished lipolysis (lower FFA, glycerol and triglycerides, as well as lower ketone body concentrations). These changes were interrelated as shown by the analyses of covariance and correlation and are in keeping with the known actions of insulin as an inhibitor of gluconeogenesis and lipolysis. These improvements were, however, independent of changes in growth 
hormone concentration, which were affected little by treatment.

Neither the absolute amount of weight lost nor the loss in \% DBW nor the duration of diet correlated with the improvement in glucose tolerance or in insulin secretion. These results agree with those of Wall et al., [23] who concluded that the improvement in glucose tolerance after diet treatment was independent of weight loss. It is known, however, that loss of weight in obese individuals can produce striking improvements in glucose tolerance and insulin sensitivity $[5,13]$, possibly by a reduction in the size of abnormally large adipose cells, [16] or an increase in the number of insulin receptors [1]. Among our patients, those who were most obese ( $>$ $115 \%$ DBW) on presentation showed the greatest improvements in glucose tolerance and insulin secretion.

Previous studies have also shown improvement in insulin secretion concurrent with improved glucose tolerance after carbohydrate restriction $[3,7,15]$. We have proposed [24] the following mechanism to explain this improvement (Fig. 5). Decreased carbohydrate intake leads directly to a lower daily mean blood glucose (BG) concentration. The stimulus to the pancreatic beta cell to secrete insulin is lowered and becomes submaximal. Assuming that insulin synthesis continues unchanged, although at a subnormal rate, synthesis can now exceed secretion and the functional reserve of the beta cell becomes partially restored. The insulin response to an oral glucose load can be increased [9]. This partial restoration of a normal insulin-glucose interrelation creates a feedback loop tending further to lower mean blood glucose. Doar et al. [3] proposed a similar mode of action of diet in improving glucose tolerance in diabetics. This hypothesis receives support from the experiments of Turner et al., [21] who showed that restoration of normoglycaemia with exogenous insulin in diabetics improved the first phase insulin response to intravenous glucose, presumably by "resting" the beta cell. The converse of this mechanism has been demonstrated in both animals and man. Dohan and Lukens [4] induced hydropic degeneration of the islets of Langerhans and a persistent diabetic state by injecting large amounts of glucose intraperitoneally into cats. The development of the islet lesions was related to the degree and duration of the hyperglycaemia and not to excessive energy intake or weight gain. In the pre-diabetic Chinese hamster, diabetes can be prevented by dietary restrictions and precipitated by ad libitum feeding [6]. Seltzer and Harris [17] infused glucose intravenously over 5-7 days into normal and diabetic subjects and demonstrated exhaustion of insulin reserve in the diabetics, but not in the normal subjects.
When the patients were arbitrarily assigned to two groups on the basis of the degree of glucose intolerance at the second OGTT, approximately $30 \%$ were found to have 'responded'. As a group, these patients had significantly improved insulin secretion after oral glucose, as well as evidence of diminished lipolysis. Non-responders did not similarly improve and appeared as a group to have evidence of a more severe diabetic state (i. e. a greater incidence of vascular disease). The clinical importance of the results is that, of patients presenting with symptomatic diabetes mellitus, one third will have sufficient improvement in glucose and fat metabolism with dietary advice alone to eliminate the need for treatment with oral hypoglycaemic agents. This may be important in view of alleged longterm hazards associated with the use of tolbutamide [22]. Our data also suggest that a period of one month's treatment with diet alone will reveal the majority of those who will benefit from this form of treatment.

Acknowledgements. We are grateful to Sister S. L Judd for performing the glucose tolerance tests, to Ms. K. Hilary Quine for measurements of insulin and growth hormone, to Ms Sandy M. Juul for measurements of free fatty acids and to J. Martin Bland, Esq. for advice on statistıcal analyses. Dr. R. R. McSwiney kindly allowed the use of the routine Clinical Chemistry services for blood glucose and cholesterol measurements. We thank Hoechst Pharmaceuticals Ltd., the Britısh Diabetic Association and St Thomas's Hospital Research (Endowments) Committee for grants in aid.

\section{References}

1. Archer, J. A, Gorden, P., Roth, J.: Defect in insulin binding to receptors. Amelioration with calorie restriction. J. Clin Invest $\mathbf{5 5}, 166-174$ (1975)

2. Carruthers, M., Young, D. A. B.: Free fatty acid estimation by a semiautomated fluonmetric method. Clin. Chim. Acta 49, 341-348 (1974)

3. Doar, J.W.H., Thompson, M.E., Wilde, C.E., Sewell, P.F J.- Influence of treatment with diet alone on oral glucose tolerance test and plasma sugar and insulın levels in patients with maturity diabetes mellitus. Lancet 1975 I, 1263-1266

4 Dohan, F C., Lukens, P.D. W.: Experimental diabetes produced by the admintstration of glucose. Endocrinology 42 , 244-262 (1948)

5. Drenick, E. J., Brickman, A. S., Gold, E.M.: Dissociatıon of the obesity-hyperinsulinism relationship following dietary restriction and hyperalimentation. Am. J. Clin. Nutr. 25, 746-755 (1972)

6. Gerritsen, G C., Blanks, M C., Needham, L B.: Prevention of diabetes in the prediabetic Chinese hamster by limitation of diet Diabetes 21, (Suppl 1), 337-338 (1972)

7. Hadden, D. R., Montgomery, D. A. D., Skelly, R. J., Trumble, E. R., Weaver, J. A, Wilson, E A., Buchanan, K. D.. Maturity onset diabetes mellitus: response to intensive dietary management. Br. Med. J. 1975 III, 276-278

8. Hohorst, H.J., Kreutz, F.H., Bucher, T: Über Metabolitgehalte und Metabolit-Konzentrationen in der Leber der Ratte Biochem. Z. 332, 18-46 (1949) 
9. Junod, A., Lambert, A.E., Stauffacher, W., Renold, A.E.: Diabetogenic action of streptozotocin: relationship of dose to metabolic response. J. Clin. Invest. 48, 2129-2139 (1969)

10. Kessler, G., Lederer, H.: Fluorimetric measurement of triglycerides. In: Automation in analytical chemistry, Technicon symposia 1965 341-344. White Plains, N. Y.: Medaid Inc. 1966

11. Kreutz, F. A.: Enzymatische Glycerinbestimmung. Klin. Wochenschr. 40, 362-363 (1962)

12. Levine, J., Morgenstern, S., Vlastelica, K.: A direct Liebermann-Burchard method for serum cholesterol. In: Automation in analytical chemistry. Technicon symposia 1967, 25-28. White Plains, N. Y.: Medaid Inc. 1968

13. Olefsky, J., Reaven, G. M., Farquhar, J.W.: Effects of weight reduction on obesity: studies of lipid and carbohydrate metabolism in normal and hyperlipoproteinaemic subjects. J. Clin. Invest. 53, 64-76 (1974)

14. Rollo, J.: An account of two cases of the diabetes mellitus, to which are added a general view of the nature of the disease and its appropriate treatment. London: T. Dilly at the Poultry 1797, cited from: Malins, J.: Clinical diabetes mellitus, p. 343. London: Eyre and Spottiswoode (Publishers) Ltd. 1968

15. Rudnick, P.A., Taylor, K.W.: Effect of prolonged carbohydrate restriction on serum-insulin levels in mild diabetes. Br. Med. J. 1965 I, 1225-1228

16. Salans, L. B., Knittle, J. L., Hirsch, J.: The role of adipose cell size and adipose tissue insulin sensitivity in the carbohydrate intolerance of human obesity. J. Clin. Invest. 47, 153-165 (1968)

17. Seltzer, H.S., Harris, V.L.: Exhaustion of insulinogenic reserve in maturity-onset diabetic patients during prolonged hyperglycaemic stress Diabetes 13, 6-13 (1964)

18. Sönksen, P.H., Tompkins, C. V., Srivastava, M.C., Nabarro, J.D.N.: A comparative study on the metabolism of human insulin and porcine proinsulin in man. Clin. Sci. Mol. Med. 45, 633-654 (1973)
19. Trinder, P.: Determination of blood glucose using an oxidaseperoxidase system with non-carcinogenic chromogen. J. Clin. Pathol. 22, 158-161 (1969)

20. Trinder, P.: Determination of blood glucose using 4-aminophenazone as oxygen receptor. J. Clin. Pathol. 22, 246 (1969)

21. Turner, R.C., McCarthy, S.T. Holman, R. R., Harris, E.: Beta-cell function improved by supplementing basal insulin secretion in mild diabetes. Br. Med. J. 1976 I, 1252-1254

22. University Group Diabetes Program: A study of the effects of hypoglycemic agents on vascular complications in patients with adult-onset diabetes. Diabetes 19 (Suppl. 11), 747-830 (1970)

23. Wall, J. R., Pyke, D. A., Oakley, W. G.: Effect of carbohydrate restriction in obese diabetics: relationship of control to weight loss. Br. Med. J. 1973 I, 577-578

24. West, T.E.T., Dron, D.E., Hay, B.J., Perkins, J. R., Lowy, C., Sonksen, P. H.: Improved insulin secretion in diabetics after carbohydrate restriction. Eur. J. Clin. Invest. 5, 15 (1975)

25. Williamson, D.H., Mellanby, J., Krebs, H. A.: Enzymatic determination of $\mathrm{D}(-)$-B-hydroxybutyric acid and acetoacetic acid in blood. Biochem. J. 82, 90-96 (1962)

26. Winer, B. J.: Statıstical principles in experimental design 2nd edn, pp, 140-224 and 578-618. London, New York, Sidney, Toronto- McGraw-Hill Publishing Co. Ltd., and Ljubljana: Mladinska Knjiga 1970

Received: November 8, 1976, and in revised form: June 23, 1977

Dr.T.E.T. West

Department of Medicine

St. Thomas's Hospital Medical School

London SE1 7EH

England 